\title{
Potential Drug-Drug Interactions in a Cohort of Elderly, Polymedicated Primary Care Patients on Antithrombotic Treatment
}

\author{
Katharina Luise Schneider ${ }^{1,2}$ (1) Kathrin Kastenmüller $^{3}$ - Klaus Weckbecker ${ }^{3}$. \\ Markus Bleckwenn $^{3} \cdot$ Miriam Böhme $^{1,2} \cdot$ Julia Carolin Stingl ${ }^{1,2}$
}

Published online: 8 May 2018

(C) The Author(s) 2018

\begin{abstract}
Introduction Drug-drug interactions (DDIs) are an important risk factor for adverse drug reactions. Older, polymedicated patients are particularly affected. Although antithrombotics have been detected as high-risk drugs for DDIs, data on older patients exposed to them are scarce.

Methods Baseline data of 365 IDrug study outpatients ( $\geq 60$ years, use of an antithrombotic and one or more additional long-term drug) were analyzed regarding potential drug-drug interactions (pDDIs) with a clinical decision support system. Data included prescription and self-medication drugs.

Results The prevalence of having one or more pDDI was $85.2 \%$. The median number of alerts per patient was three (range $0-17$ ). For $58.4 \%$ of the patients, potential severe/contraindicated interactions were detected. Antiplatelets and non-steroidal anti-inflammatory drugs (NSAIDs) showed the highest number of average pDDI alert involvements per use (2.9 and 2.2, respectively). For NSAIDs, also the highest average number of severe/contraindicated alert involvements per use (1.2) was observed. $91.8 \%$ of all pDDI involvements concerned the 25 most frequently used drug classes. $97.5 \%$ of the
\end{abstract}

Katharina Luise Schneider

katharina.schneider@bfarm-research.de

1 Research Division, Federal Institute for Drugs and Medical Devices, Kurt-Georg-Kiesinger-Allee 3, 53175 Bonn, Germany

2 Centre for Translational Medicine, Medical Faculty of the University of Bonn, Sigmund-Freud-Str. 25, 53127 Bonn, Germany

3 Institute of General Practice and Family Medicine, Medical Faculty of the University of Bonn, Sigmund-Freud-Str. 25, 53127 Bonn, Germany severe/contraindicated pDDIs were attributed to only nine different potential clinical manifestations. The most common management recommendation for severe/contraindicated pDDIs was to intensify monitoring. Number of drugs was the only detected factor significantly associated with increased number of pDDIs $(p<0.001)$.

Conclusion The findings indicate a high risk for pDDIs in older, polymedicated patients on antithrombotics. As a consequence of patients' frequently similar drug regimens, the variety of potential clinical manifestations was small. Awareness of these pDDI symptoms and the triggering drugs as well as patients' self-medication use may contribute to increased patient safety.

\section{Key Points}

$85.2 \%$ of the elderly, polymedicated primary care patients on antithrombotic treatment in our study had at least one potential drug-drug interaction (pDDI).

The variety of drugs that could trigger pDDIs and the potential clinical consequences of severe/contraindicated pDDIs was small in our cohort.

Treating physicians should always be informed about the patient's self-medication use and include these drugs in their pDDI risk evaluation. 


\section{Introduction}

Drug-drug interactions (DDIs) are a highly relevant topic in the treatment of older patients, who are frequently affected by multimorbidity and subsequent polypharmacy $[1,2]$, which increases the risk, especially if several prescribers are involved [3]. Notably, only some of the potential drug-drug interactions (pDDIs) result in actual adverse events $[4,5]$. However, among other factors, such as polypharmacy, age and female sex, DDIs have been identified as risk factors for adverse drug reactions (ADRs) in elderly patients [6]. In literature reviews, a prevalence rate of about $10 \%$ for ADR-related hospital admissions has been reported for older patients [7] and about 5\% of the hospital admissions of elderly have been estimated to be caused by DDIs [8]. Still, data concerning this issue seem to vary greatly. In a recent prospective, cross-sectional study on unplanned hospital admissions in older patients, $88.5 \%$ of the ADR-associated cases were considered to be preventable, $2.1 \%$ were fatal and $42.9 \%$ were potentially DDI associated [9].

Studies indicate that the implementation of a clinical decision support system (CDSS) can reduce the prevalence of potentially serious DDIs [10], inappropriate prescribing to elderly patients [11] and DDI-related ADRs in populations without age limit as well as older multimorbid populations [12, 13]. However, in primary care, a regular comprehensive medication review is not performed routinely, although the patients' long-term treatments are usually supervised by the general practitioner (GP). This issue is also addressed in the IDrug study, a randomized controlled trial evaluating the effect of an individualized risk assessment (including pDDIs) on ADRs in a cohort of elderly, polymedicated primary care patients on antithrombotic treatment (chosen as high-risk index drugs) [14]. Antithrombotics, cardiovascular drugs and non-steroidal anti-inflammatory drugs (NSAIDs) have been described to be the drug classes which are most frequently involved in DDI-related emergency department visits and hospital admissions [8, 15]. An analysis in Dutch community pharmacies indicated that the majority of pDDIs appear in a minority of patients and that antithrombotic agents were the drug class which most commonly led to pDDIs [16]. Still, publications on pDDIs usually investigate general populations [3, 4, 17-23], and data focusing on a vulnerable elderly population exposed to high-risk drugs are sparse. The objective of this analysis was to investigate the prevalence of pDDIs and particularly severe/contraindicated pDDIs in a cohort of elderly primary care patients (IDrug study population) as well as to identify drug classes and patient factors associated with an increased number of pDDIs. Apart from the scarcity of data focusing on patients on high-risk medications, previous studies on pDDIs have often been based on prescription data $[3,19,20,24,25]$, and if data were directly obtained from patients or their GP, they usually did not include over-the-counter (OTC) medications and nutritional supplements [21, 26]. Furthermore, publications are often based on data from hospitalized patients [17, 18, 22, 23], which do not represent the patients' actual long-term medication, as it is frequently changed upon admission [27] and after discharge [28]. Thus, the aim of this analysis was to evaluate the risk of pDDIs in real-world conditions by analyzing comprehensive data of drug regimens including self-medication from a community-dwelling, elderly patient cohort at high risk for ADRs that can be found commonly in primary care.

\section{Methods}

\subsection{Data Collection}

Baseline demographic and medication data of all 365 patients who were enrolled and randomized in the IDrug study [14] between September 2014 and March 2017 were analyzed. Study sites were 43 general practices in the area of Bonn, Cologne and the Rhine-Sieg district, Germany. Inclusion criteria of the study were ability to give informed consent, age $\geq 60$ years, multimorbidity and use of two or more long-term medications, one of which had to be an antithrombotic agent (high-risk index drugs). Upon enrollment, all medication data of the previous 3 months were collected. This included both prescription and OTC drugs as well as nutritional supplements, which were obtained from the electronic health records and the patients' self-medication disclosures. The self-medication disclosure was a pocket-sized card that was taken home and filled in by all patients upon enrollment and continuously updated during follow-up. The patients were asked to record all medications and nutritional supplements that were either purchased "over the counter" or prescribed by a doctor other than their GP. Vitamin, mineral and phytopharmaceutical preparations were generally included in the IDrug study and subsequently in this analysis to detect their involvement in interactions; homeopathic agents, however, were excluded as their potential for DDIs and ADRs was anticipated to be low.

\subsection{Detection of Potential Drug-Drug Interactions (pDDIs)}

The patients' drug regimens were assessed for pDDIs using the AiDKlinik ${ }^{\circledR}$ interaction tool, a referenced and continuously updated online CDSS developed by the University 
of Heidelberg, Germany [29]. It provides information on more than 22,500 interacting drug pairs. The program generates pDDI alerts involving two to three active substances each and provides information on the underlying mechanism, potentially resulting ADR (pADR), severity and clinical management. Every single agent can interact with several others. Whenever there was multiple use of one substance in a patient's regimen (e.g., duplicate prescriptions or the medication was taken twice daily in different dosages/drug compositions), the tool considered each use separately and generated multiple redundant alerts. In the analysis, however, the rare cases of duplicate alerts involving the same substances were counted as one. If a drug was administered topically and had no potential for systemic interactions, this was considered both in interaction (automatically incorporated in the tool) and in quantitative analysis (by attributing it to a different drug class than the systemically administered equivalent, e.g., topical vs. systemic corticosteroids).

The tool categorizes the pDDI severity into "contraindicated/high-risk combination," "clinically severe interaction," "potentially clinically relevant, moderate interaction," "mild, rarely clinically relevant interaction," "contradictive studies/findings" and "studies showed no clinically relevant interactions." The latter were not included in the analysis since they provide evidence for the absence of pDDIs.

\subsection{Medication Analysis}

In quantitative and interaction analysis, all active agents were considered separately if combination products of conventional drugs (e.g., ramipril and hydrochlorothiazide) were used. However, combination products of vitamins, minerals or phytopharmaceuticals were counted as one in quantitative analysis (not in interaction analysis), accounting for their frequently large number of components, which would have biased the number of drugs per patient. As in interaction analysis, multiple uses of the same drug in one patient were counted as one. For a structured illustration of the drugs' involvement in pDDIs, the analyses were performed by drug classes. In contrast to individual drugs, drug classes could occur multiple times in one patient (e.g., concomitant therapy with clopidogrel and acetylsalicylic acid was counted as use of two antiplatelets in one patient). The average number of alert involvements per use was calculated for each drug class. For this purpose, the number of alerts that the drug class was involved in was divided by the number of cases that the drug class was used by the patients.

\subsection{Statistical Analysis}

Statistical analysis was performed using IBM $^{\circledR}$ SPSS $^{\circledR}$ Statistics for Windows, Version 21.0. Armonk, NY, USA; IBM Corp. For correlation analysis Spearman's rank correlation was used. Comparison between males and females was performed with Mann-Whitney $U$ test for independent samples. All tests were two-sided. $P$ values $\leq 0.05$ were considered statistically significant.

\subsection{Trial Registration}

The IDrug study was registered with the German Clinical Trials Register on January 9, 2015 (ID: DRKS00006256).

\section{Results}

\subsection{Frequency and Severity of pDDIs}

A total of 1426 alerts in 365 patients were generated by the tool. Of these, 1332 pDDIs (93.4\%) involved two and 94 pDDIs (6.6\%) included three substances. The median number of alerts per patient was three [range 0-17, interquartile range (IQR) 1-6]. For $85.2 \%$ of the patients, at least one pDDI was detected. The distribution of pDDIs per patient is illustrated in Fig. 1.

A total of 409 alerts $(28.7 \%)$ were categorized as severe, $592(41.5 \%)$ were moderate and $349(24.5 \%)$ were mild. Potential DDIs based on contradictive data were rarer, with 69 cases $(4.8 \%)$. Contraindications occurred in only seven alerts $(0.5 \%)$. The substances in question were amiodarone and citalopram (two cases; pADR: long-QT-syndrome), erythromycin and simvastatin (one case; pADR: myopathy/ rhabdomyolysis), low-molecular-weight heparins and apixaban (two cases; pADR: bleeding), eplerenone and potassium (one case; pADR: hyperkalemia) and carbamazepine and nisoldipine (one case; pADR: reduced nisoldipine effectiveness). Taken together the prevalence of at least one severe or contraindicated pDDI in the 365 patients was $58.4 \%(n=213) .41 .6 \%$ of the patients did not have any severe/contraindicated pDDIs, $52.3 \%$ had one to three, $5.8 \%$ had four to six and one patient $(0.3 \%)$ had eight.

\subsection{Drug Classes Involved}

In total, use of 3311 drugs was documented for the 365 study patients. After categorization, the 25 most frequent drug classes covered $78.5 \%$ of all medications taken in this cohort. $\beta$-Blockers, vitamin $\mathrm{K}$ antagonists, statins, thiazidetype diuretics and angiotensin-converting enzyme inhibitors (ACEIs) were the most commonly used drug groups. 
Fig. 1 Number of pDDI per patient. $p D D I$ potential drugdrug-interaction

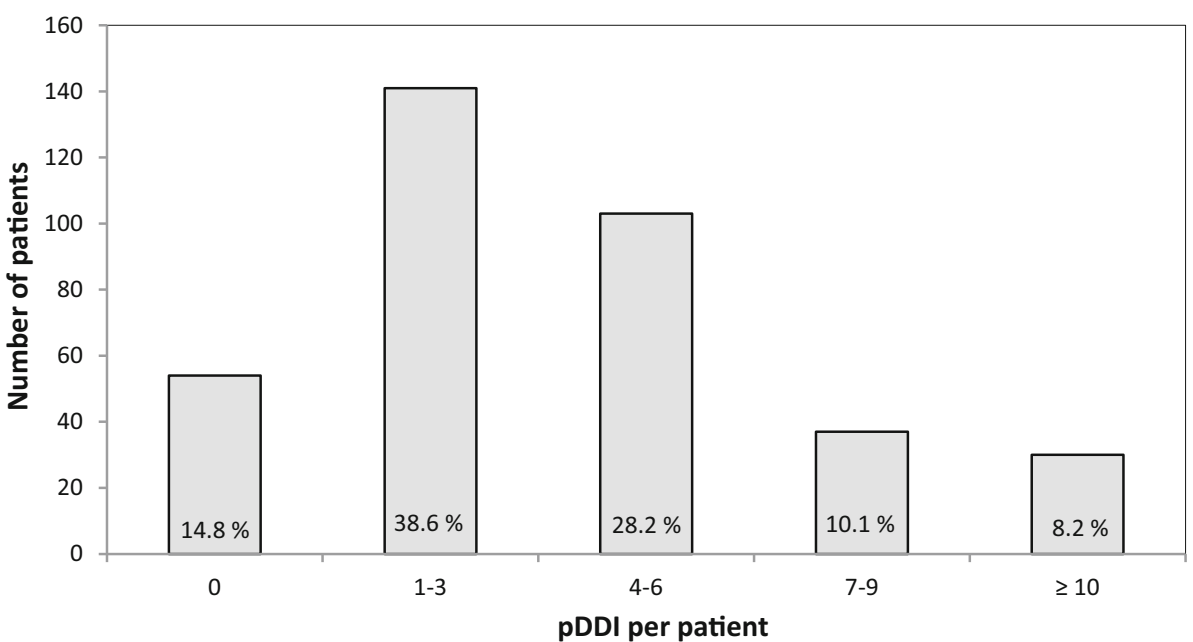

Antiplatelets and NSAIDs showed the highest average number of alert involvements per use (2.9 and 2.2, respectively), followed by vitamin $\mathrm{K}$ antagonists (1.8) and uricostatics (1.7). NSAIDs were additionally the drug class that was most frequently involved in severe/contraindicated pDDIs with regard to their use (1.2 severe/contraindicated pDDI involvements per use). Other drug classes with a high average number of severe/contraindicated pDDI involvements per use were potassium-sparing diuretics (1.0) and antiplatelets (0.8). For novel oral anticoagulants (NOACs) the average number of pDDI involvements per use was rather low (0.3).

Minerals and vitamins were the most commonly used non-prescription agents in this cohort and ranged among the ten most frequent substance classes. Whilst vitamins demonstrated only an average of 0.1 pDDI involvements per use and did not contribute to any severe/contraindicated alerts, minerals (predominantly magnesium, potassium and calcium) had an average of 0.7 general and 0.2 severe/contraindicated pDDI involvements per use. A large variety of phytopharmaceutical preparations was found among the drug regimens. They were grouped according to the medical condition they were used for. The most frequent indications were common cold $(n=24$, miscellaneous substances), unrest ( $n=18$, mostly valerian and/or hops), cardiac issues ( $n=11$, mostly camphor and/or Crataegus), gastrointestinal symptoms $(n=9$, miscellaneous substances) and obliviousness ( $n=7$, ginkgo). Among the 1426 alerts, 19 pDDIs with phytopharmaceutical involvement were detected. Two of them were classified as "severe" (verapamil/ $\beta$-acetyldigoxin and St. John's wort); all of them included either ginkgo $(n=12)$ or St. John's wort $(n=7)$.

Of all pDDI alert involvements (2946 drugs were involved in the 1426 alerts), $91.8 \%$ could be attributed to the 25 most frequently used substance classes. Other drug classes that were less often used but showed a high average number of pDDI alert involvements per use were digitalis glycosides (2.1) and disease-modifying anti-rheumatic drugs (2.7). Figure 2 gives an overview of the 25 most frequently used drug classes, their number of uses, number of alerts and number of severe/contraindicated alerts.

\subsection{Characteristics of Severe/Contraindicated pDDIs}

$97.5 \%$ of the severe/contraindicated pDDIs $(n=416)$ were related to a variety of only nine different pADRs, which were bleeding (39.1\%), renal impairment $(19.5 \%)$, hyperkalemia (11.8\%), myopathy/rhabdomyolysis $(6.0 \%)$, digitalis toxicity $(5.5 \%)$, cardiac arrhythmia/bradycar$\mathrm{dia} /$ heart failure $(5.0 \%)$, leukopenia $(4.8 \%)$, cardiovascular events/reduced anticoagulation $(3.8 \%)$ and methotrexate toxicity $(1.9 \%)$. Only $2.6 \%$ were related to other pADRs. Alerts for bleeding complications were mostly induced by combinations of vitamin $\mathrm{K}$ antagonists and levothyroxine, NSAIDs or antiplatelets. Drug combinations causing an alert for renal impairment were always a triplet of a diuretic (loop, thiazide or potassium-sparing diuretic), an inhibitor of the renin-angiotensin system, i.e., ACEI or angiotensin-II subtype-1 (AT1) inhibitor, and an NSAID or acetylsalicylic acid. Hyperkalemia alerts were mostly based on combinations of potassium-sparing diuretics or potassium with an inhibitor of the renin-angiotensin system (ACEI or AT1 inhibitor) or with each other. Table 1 demonstrates the nine most frequent pADRs and the relating $\mathrm{pDDIs}$.

\subsection{Management of Severe/Contraindicated pDDIs}

Management recommendations in cases of severe/contraindicated pDDI $(n=416)$ given by the CDSS tool 
Fig. 2 Number of uses, alerts and severe/contraindicated alerts of the 25 most common substances. The numbers above each column indicate the average number of pDDIs per use (top) and the average number of

severe/contraindicated pDDIs per use (bottom). ACEI angiotensin-converting enzyme inhibitor, $A T 1$ angiotensin-II subtype-1, NOAC novel oral anticoagulant, NSAID nonsteroidal anti-inflammatory drug, $p D D I$ potential drug-drug interaction, $P P I$ proton pump inhibitor. ${ }^{1}$ Antithrombotic treatment was one of the inclusion criteria of the IDrug study [14]

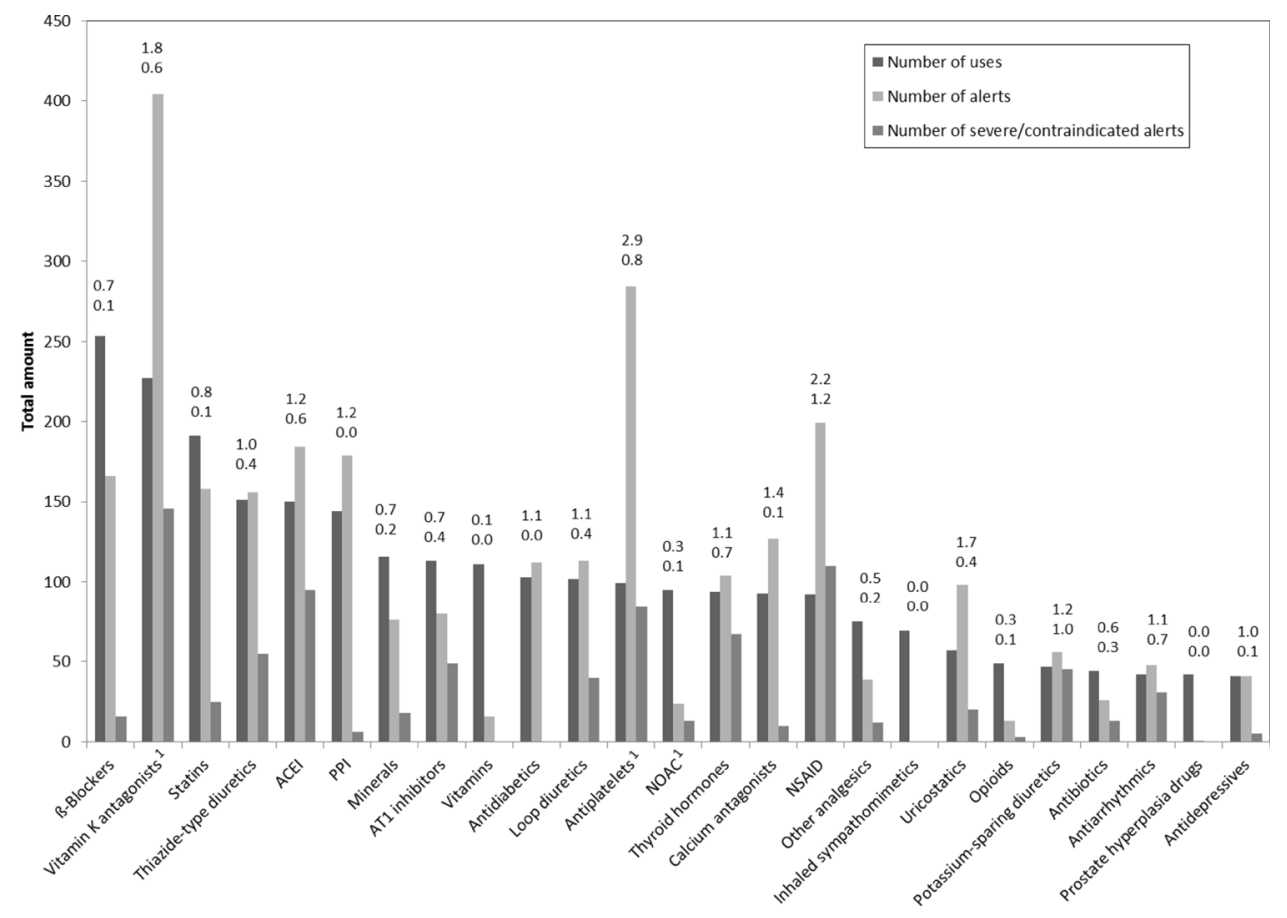

frequently involved two or more alternative possibilities (i.e., percentages add up to more than $100 \%$ ), e.g., either changing the drug or intensifying monitoring if drug replacement was considered impossible. The most frequent advice was to intensify monitoring (e.g., international normalized ratio, potassium, renal function, etc.). It was given in $310(74.5 \%)$ of the cases. One hundred and ninetyeight $(47.6 \%)$ of the recommendations included discontinuation or replacement of a drug. However, only 20 of them $(4.8 \%$ of all recommendations for severe/contraindicated pDDIs) did not provide any alternative approach. These included the seven cases of contraindications. One hundred and forty-three (34.4\%) of the severe/contraindicated pDDIs led to dosing recommendations. In 79 cases $(19.0 \%)$, the management strategy included adding another drug to the regimen. All of them concerned either proton pump inhibitors to reduce the risk of gastrointestinal bleeding or potassium supplementation when combining digitalis glycosides and potassium-depleting diuretics. Other approaches were rare; there were ten recommendations $(2.4 \%)$ to avoid taking the interacting drugs at once (e.g., by leaving $2 \mathrm{~h}$ in between) and one that suggested reducing sotalol gradually before tapering off clonidine to prevent withdrawal symptoms.

\subsection{Factors Associated with pDDIs}

Three demographic factors were evaluated: age, sex and number of drugs. The median age was 75 years (range 60-91, IQR 70.5-80) and the median number of active substances per patient was nine (range 2-30, IQR 6-11). $59.2 \%$ of the study cohort were men; $40.8 \%$ were women. No significant correlation between age and the number of drugs $\left(r_{\mathrm{s}}=0.02, p=0.64\right)$ or age and the number of pDDIs was found $\left(r_{\mathrm{s}}=-0.04, p=0.49\right)$. There was also no significant difference between the two sexes regarding number of pDDIs $(p=0.16)$. The number of substances and the number of alerts were positively correlated $\left(r_{\mathrm{s}}\right.$ $=0.63, p<0.001)$. However, plotting the number of drugs against the number of pDDIs (Fig. 3) showed that there was a stronger increase when the number of drugs was smaller compared to larger drug regimens.

\section{Discussion}

Our analysis of pDDIs in the IDrug study cohort indicates that the potential for interactions is high in elderly, polymedicated patients on antithrombotics. The prevalence of having at least one pDDI was $85.2 \%$, the median number of alerts per patient was three (range $0-17$, IQR 1-6) and ten or more alerts were seen in $8.2 \%$ of the patients. Additionally, more than half of the population $(58.4 \%)$ had at least one potential severe/contraindicated interaction. Previous investigations on this subject were typically based on general populations [3, 4, 17-23], not on patients at particular risk. However, a publication on pDDIs in Dutch community pharmacies indicated that pDDIs are strongly clustered within a minority of individuals [16]. This suggests that elaborate studies on high-risk groups are needed. 
Table 1 Frequencies of the nine most common pADRs and the triggering pDDIs

\begin{tabular}{|c|c|c|c|c|}
\hline pADR & $\begin{array}{l}\text { pADR } \\
\text { frequency }\end{array}$ & Active substances 1 & Active substances $2(+3)$ & $\begin{array}{l}\mathrm{pDDI} \\
\text { frequency }\end{array}$ \\
\hline \multirow[t]{11}{*}{ Bleeding } & \multirow[t]{11}{*}{163} & Vitamin $\mathrm{K}$ antagonists & Levothyroxine & 68 \\
\hline & & NOAC & NSAID & 48 \\
\hline & & Systemic glucocorticoids & Antiplatelets & 25 \\
\hline & & \multirow[t]{8}{*}{ Acetylsalicylic acid } & Antibiotic & 3 \\
\hline & & & Acetaminophen & 1 \\
\hline & & & Acetylsalicylic acid & 8 \\
\hline & & & Amiodarone & 2 \\
\hline & & & Heparin & 2 \\
\hline & & & NSAID & 4 \\
\hline & & & Acetylsalicylic acid & 1 \\
\hline & & & NSAID & 1 \\
\hline Renal impairment & 81 & $\begin{array}{l}\text { Loop diuretics or thiazide diuretics or } \\
\text { potassium-sparing diuretics }\end{array}$ & $\begin{array}{l}\text { ACEI or AT1 antagonists + NSAID } \\
\text { or acetylsalicylic acid }\end{array}$ & 81 \\
\hline \multirow[t]{10}{*}{ Hyperkalemia } & \multirow[t]{10}{*}{49} & Potassium-sparing diuretics & ACEI & 15 \\
\hline & & Potassium & ACEI + loop diuretic & 1 \\
\hline & & Co-trimoxazole & AT1 antagonists & 10 \\
\hline & & \multirow[t]{7}{*}{ Amiodarone } & Potassium & 4 \\
\hline & & & ACEI & 9 \\
\hline & & & AT1 antagonists & 6 \\
\hline & & & Potassium-sparing diuretic & 1 \\
\hline & & & Ramipril & 1 \\
\hline & & & Valsartan & 1 \\
\hline & & & Eplerenone & 1 \\
\hline \multirow[t]{7}{*}{ Myopathy/rhabdomyolysis } & \multirow[t]{7}{*}{25} & \multirow[t]{7}{*}{ Statins } & Amiodarone & 9 \\
\hline & & & Ticagrelor & 4 \\
\hline & & & Verapamil & 4 \\
\hline & & & Dronedarone & 3 \\
\hline & & & Ranolazine & 3 \\
\hline & & & Erythromycin & 1 \\
\hline & & & Diltiazem & 1 \\
\hline \multirow[t]{3}{*}{ Digitalis toxicity } & \multirow[t]{3}{*}{23} & \multirow[t]{3}{*}{ Digitalis glycosides } & Thiazide diuretics & 12 \\
\hline & & & Loop diuretics & 10 \\
\hline & & & Verapamil & 1 \\
\hline \multirow{8}{*}{$\begin{array}{l}\text { Arrhythmia/bradycardia/heart } \\
\text { failure }\end{array}$} & \multirow[t]{8}{*}{21} & Amiodarone & $\beta$-Blockers & 13 \\
\hline & & Thiazide diuretics & Citalopram & 2 \\
\hline & & Propafenone & Ciprofloxacin & 1 \\
\hline & & Verapamil & Sotalol & 1 \\
\hline & & \multirow[t]{4}{*}{ Amitriptyline } & Co-trimoxazole & 1 \\
\hline & & & Metoprolol & 1 \\
\hline & & & Nebivolol & 1 \\
\hline & & & Ranolazine & 1 \\
\hline
\end{tabular}


Table 1 continued

\begin{tabular}{|c|c|c|c|c|}
\hline pADR & $\begin{array}{l}\text { pADR } \\
\text { frequency }\end{array}$ & Active substances 1 & Active substances $2(+3)$ & $\begin{array}{l}\mathrm{pDDI} \\
\text { frequency }\end{array}$ \\
\hline Leukopenia & 20 & Allopurinol & ACEI & 20 \\
\hline \multirow{4}{*}{$\begin{array}{l}\text { Cardiovascular events/ } \\
\text { reduced anticoagulation }\end{array}$} & \multirow[t]{4}{*}{16} & Clopidogrel & Omeprazole & 5 \\
\hline & & Acetylsalicylic acid & Metamizole & 7 \\
\hline & & Rivaroxaban & NSAID & 3 \\
\hline & & & Carbamazepine & 1 \\
\hline \multirow[t]{4}{*}{ Methotrexate toxicity } & \multirow[t]{4}{*}{8} & \multirow[t]{4}{*}{ Methotrexate } & NSAID & 3 \\
\hline & & & Metamizole & 3 \\
\hline & & & Acetylsalicylic acid & 1 \\
\hline & & & Omeprazole & 1 \\
\hline
\end{tabular}

$A C E I$ angiotensin-converting enzyme inhibitor, ATl angiotensin-II subtype-1, NOAC novel oral anticoagulant, NSAID non-steroidal antiinflammatory drug, $p A D R$ potentially resulting adverse drug reaction, $p D D I$ potential drug-drug-interaction

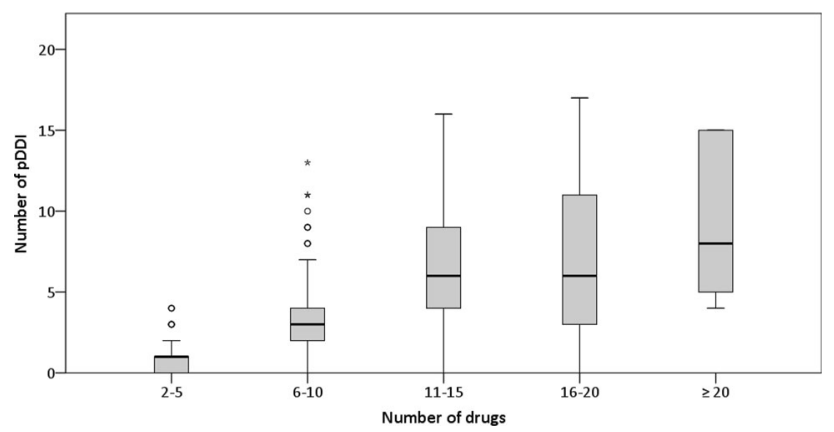

Fig. 3 Number of pDDIs stratified by number of drugs. Each box demonstrates IQR and median; whiskers represent values within $1.5 \times \mathrm{IQR}$ or, if there are none, minimum/maximum values. Circles and stars indicate outliers $(>1.5 \times \mathrm{IQR})$ and extreme outliers $(>3 \times \mathrm{IQR})$, respectively. IQR interquartile range, $p D D I$ potential drug-drug-interaction

Studies on elderly who were on at least two drugs reported prevalence rates of $44.5 \%$ for pDDIs [5] and about 5-16\% for potentially severe pDDIs $[24,25,30]$. In a publication on older patients on at least four drugs, the average number of pDDIs per patient was 1.55 [20]. Compared to these studies the risk in our cohort is remarkably higher, which may be attributable to the antithrombotic treatment. Publications focusing on elderly patients on particular high-risk medications are rarer. A study on older patients using NSAIDs indicated that there is a wide concomitant use of NSAIDs and antithrombotic agents [31]. Still, even though antithrombotic drugs have been described to be the most commonly involved drugs in DDI-related hospital visits [15] and the drug class that most frequently led to pDDIs in community pharmacies [16], detailed data focusing on pDDIs in older patients exposed to these potentially risky medications are scarce.
It can be assumed that more commonly used drugs automatically created a higher number of alerts. To approach the question how often a certain drug class was involved in pDDIs with regard to its use, we calculated the average number of pDDI involvements per use. This approach revealed that the high number of pDDIs and severe/contraindicated pDDIs involving vitamin $\mathrm{K}$ antagonists was not only due to the high prescription rates in this population. Their ratios were 1.8 and 0.6 , which means that on average every use resulted in 1.8 pDDIs and $0.6 \mathrm{sev}$ ere/contraindicated pDDIs. In comparison, NOAC showed rather low average numbers of general $(0.3)$ and severe/contraindicated pDDI involvements per use (0.1). Other drug classes with a high average number of pDDI involvements per use and severe/contraindicated pDDI involvements per use were antiplatelets (2.9 and 0.8) and NSAIDs (2.2 and 1.2). In comparison, $\beta$-blockers, which represented the most frequently prescribed drug class, showed a smaller average number of pDDI involvements (0.7) and severe/contraindicated pDDI involvements (0.1) per use. When interpreting these results, it needs to be considered that the inclusion criteria of antithrombotic treatment increased the absolute numbers of uses and subsequently of pDDIs. Drug classes that typically interact with them (e.g., NSAIDs) were affected by this as well, because it can be assumed that the number of pDDI alert involvements also increases if an interacting counterpart (in this case antithrombotics) is used more frequently than usual. Accordingly, our results can only be interpreted for patients on antithrombotics. The average number of alert involvements per use may also have been influenced by the fact that some interacting drug classes are frequently prescribed in combination or that patients on certain medications might be more likely to have larger drug regimens. 
However, these factors naturally appear in real-life conditions and therefore reflect daily clinical practice.

There was a significant association between the number of drugs and the number of alerts, which is in concordance with other publications $[3,17,24,25]$ and seems to be highly plausible assuming that adding a drug to a regimen increases the likelihood of an interaction. However, there seems to be a stronger increase in smaller drug regimens than in larger ones when plotting the number of drugs against the number of pDDIs. It has to be considered that there were fewer individuals in the group of patients on larger drug regimens and that the number of pDDIs varied widely among them. Nevertheless, the same effect has been seen in another publication with a larger sample size [32]. Thus, it might be hypothesized that the frequently assumed strong escalation of pDDIs with increasing number of drugs only applies when comparing smaller drug regimens and that the steepness levels out when regimens consist of about 16-20 drugs. In contrast to the number of drugs, age and sex showed no significant association with the number of pDDIs. For both factors, current data seem to be inconclusive in the literature. Higher pDDI risks for older [17, 24] as well as younger $[25,30]$ patients have been described, and lower [25] as well as higher [17] risks have been reported for women, whilst others did not see any difference between the sexes [24,30].

This analysis has some limitations. Notably, it has been shown that there are clear discrepancies between electronic DDI databases [33], which is why the results of pDDI analyses depend on the software that has been used for detection. Additionally, for drugs that have been on the market only for a short time, clinical long-term experiences concerning pDDIs may be limited. Apart from that, the CDSS used in our study did not include medication dosages in the pDDI analysis, when these might have had an influence in some cases (e.g., low-dose acetylsalicylic acid vs. analgesic dosages in combination with ACEI and diuretics). There was also no judgment on our part whether the concomitant use of interacting drugs was justified since the study design intended to leave this to the GP's discretion. Moreover, it cannot be ruled out that drug pairs were considered interacting although they were not taken concomitantly. This problem particularly applies to selfmedication drugs that were often not taken on a regular basis but only on-demand. Nevertheless, for all regular medications prescribed by the GP, there were only very few changes documented. Thus, most of the drugs were continuously taken over the 3-month period prior to enrollment, and "false" alerts of this kind were most likely very rare in our analysis. Additionally, whenever a patient has two interacting drugs available, even if only on-demand, the potential for a DDI is always imminent.

One of the strengths of this study is the comprehensiveness of the collected medication data. In most of the analyses concerning DDIs, the data are taken from prescription databases [3, 19, 20, 24, 25], which do not include OTC drugs, phytopharmaceuticals and nutritional supplements. Conversely, our analysis is based on a clinical trial where the participants were asked to record all their OTC drugs and nutritional supplements. Other publications that also included patients' self-reported OTC use were rare and seemed to detect fairly high pDDI risks as well. In a publication by Butkiewicz et al. [32], the average number of interactions per drug regimen was 2.68, and Secoli et al. [26] reported a pDDI prevalence of $54.9 \%$ in elderly, polymedicated patients. The importance of the inclusion of OTC medication is also reflected in the analysis of the evoking drugs. The relevance of minerals for pDDIs has already been indicated in a prescription-based study [10], which was also seen in our results. However, most of the mineral preparations taken in our population were freely available products and they were only documented in the patients' self-medication disclosures, not in their electronic health records. Therefore, pDDIs involving minerals might frequently not be detectable for the physicians. The same problem applies to NSAIDs, the drug class with the highest average number of severe/contraindicated pDDIs per use in our analysis. In a prospective study of ADR-related hospital admissions, they were described to be the major cause of OTC-related DDIs and ADRs [34]. The presented results emphasize that knowledge of all drugs taken by the patient, including OTC and nutritional supplements, is crucial for a comprehensive safety evaluation.

The issue of implementing pDDI alerts from CDSSs in everyday practice can be challenging. Not all pDDIs necessarily lead to ADRs, and in some cases, physicians decide to take the risk of a potential interaction in order to avoid undertreatment [5]. Studies report override rates of about $60 \%$ to more than 90\% [35-37]. Apart from that, many healthcare providers have not implemented a CDSS for different reasons, e.g., financial, technical or workflow matters [38]. As a consequence, it can be important to be aware of the most common pDDIs, particularly the severe or contraindicated ones. Our analysis suggests that the vast majority of all pDDIs in elderly primary care patients on antithrombotics are caused by the most commonly used substance classes and that within the subgroup of severe/contraindicated pDDIs, there is only a small variety of clinical manifestations as potential results. A probable reason for that might be the similarity of drug regimens in older patients with cardiovascular conditions. Awareness of the detected nine most common severe or contraindicated pDDI-related pADRs and the respective avoidance strategies (the most frequent advice was intensifying patient monitoring) might in itself contribute considerably to patients' safety. This assumption is underlined by a recent Australian study in older patients [9]. In this 
publication, the ADRs with fatal outcomes (mostly caused by drug combinations) were acute renal failure, pancytopenia, digitalis toxicity and hypotension/arrhythmia, and bleeding was one of the common pDDI-related ADRs. These results are highly in concordance with the nine most frequent pADRs found in our study. However, more data are needed on this subject and further analyses of the IDrug study data are planned after trial close-out to evaluate the effect of the anticipated drug interaction risk on the eventual occurrence of ADRs.

\section{Conclusion}

In our IDrug study cohort, pDDIs in general and severe/contraindicated pDDIs were very common. Antiplatelets and vitamin $\mathrm{K}$ antagonists, but also OTC drugs such as NSAIDs, were frequently involved in pDDI alerts. The variety of pDDI-triggering drugs and the severe potential clinical consequences appeared to be small. Treating physicians should be aware of these drug combinations and the corresponding pADR symptoms to increase patient safety. They should also be well-informed about their patients' OTC use.

Acknowledgements We would like to thank Prof. Walter Haefeli from the University of Heidelberg for providing the AiDKlinik ${ }^{\circledR}$ clinical decision support system and Dr. Ann-Kristin Leuchs for critically revising the manuscript. We also thank the general practitioners and their staff who participated in the study as well as all IDrug study team members who contributed to patient recruitment, data management and monitoring.

\section{Compliance with Ethical Standards}

Funding The IDrug study is financially supported by a research grant from the Federal Ministry of Education and Research (Grant Number 01GY1333A). Our application for a Post-Grant-Fund from the Federal Ministry of Education and Research for payment of the open access fee is currently being processed.

Conflict of interest Katharina Luise Schneider, Kathrin Kastenmüller, Klaus Weckbecker, Markus Bleckwenn, Miriam Böhme and Julia Carolin Stingl declare that they have no conflict of interest with the content of this study.

Ethical approval All procedures performed in studies involving human participants were in accordance with the ethical standards of the ethics committees of the University of Bonn, of the Medical Association of North Rhine and of the Medical Association of Rhineland-Palatinate and with the 1964 Helsinki declaration and its later amendments or comparable ethical standards.

Informed consent Informed consent was obtained from all individual participants included in the IDrug study.

Open Access This article is distributed under the terms of the Creative Commons Attribution-NonCommercial 4.0 International License (http://creativecommons.org/licenses/by-nc/4.0/), which permits any noncommercial use, distribution, and reproduction in any medium, provided you give appropriate credit to the original author(s) and the source, provide a link to the Creative Commons license, and indicate if changes were made.

\section{References}

1. Violan C, Foguet-Boreu Q, Flores-Mateo G, Salisbury C, Blom J, Freitag M, et al. Prevalence, determinants and patterns of multimorbidity in primary care: a systematic review of observational studies. PLoS One. 2014;9(7):e102149.

2. Maher RL, Hanlon J, Hajjar ER. Clinical consequences of polypharmacy in elderly. Expert Opin Drug Saf. 2014;13(1):57-65.

3. Bjerrum L, Gonzalez Lopez-Valcarcel B, Petersen G. Risk factors for potential drug interactions in general practice. Eur J Gen Pract. 2008;14(1):23-9.

4. Chen YF, Avery AJ, Neil KE, Johnson C, Dewey ME, Stockley IH. Incidence and possible causes of prescribing potentially hazardous/contraindicated drug combinations in general practice. Drug Saf. 2005;28(1):67-80.

5. Tulner LR, Frankfort SV, Gijsen GJ, van Campen JP, Koks CH, Beijnen JH. Drug-drug interactions in a geriatric outpatient cohort: prevalence and relevance. Drugs Aging. 2008;25(4):343-55.

6. Alhawassi TM, Krass I, Bajorek BV, Pont LG. A systematic review of the prevalence and risk factors for adverse drug reactions in the elderly in the acute care setting. Clin Interv Aging. 2014;9:2079-86.

7. Kongkaew C, Noyce PR, Ashcroft DM. Hospital admissions associated with adverse drug reactions: a systematic review of prospective observational studies. Ann Pharmacother. 2008;42(7):1017-25.

8. Becker ML, Kallewaard M, Caspers PW, Visser LE, Leufkens HG, Stricker BH. Hospitalisations and emergency department visits due to drug-drug interactions: a literature review. Pharmacoepidemiol Drug Saf. 2007;16(6):641-51.

9. Parameswaran Nair N, Chalmers L, Bereznicki BJ, Curtain C, Peterson GM, Connolly M, et al. Adverse drug reaction-related hospitalizations in elderly Australians: a prospective cross-sectional study in two Tasmanian hospitals. Drug Saf. 2017;40(7):597-606.

10. Andersson ML, Bottiger Y, Lindh JD, Wettermark B, Eiermann B. Impact of the drug-drug interaction database SFINX on prevalence of potentially serious drug-drug interactions in primary health care. Eur J Clin Pharmacol. 2013;69(3):565-71.

11. Terrell KM, Perkins AJ, Dexter PR, Hui SL, Callahan CM, Miller DK. Computerized decision support to reduce potentially inappropriate prescribing to older emergency department patients: a randomized, controlled trial. J Am Geriatr Soc. 2009;57(8):1388-94.

12. Bertsche T, Pfaff J, Schiller P, Kaltschmidt J, Pruszydlo MG, Stremmel W, et al. Prevention of adverse drug reactions in intensive care patients by personal intervention based on an electronic clinical decision support system. Intensive Care Med. 2010;36(4):665-72.

13. O'Sullivan D, O'Mahony D, O'Connor MN, Gallagher P, Gallagher J, Cullinan $\mathrm{S}$, et al. Prevention of adverse drug reactions in hospitalised older patients using a software-supported structured pharmacist intervention: a cluster randomised controlled trial. Drugs Aging. 2016;33(1):63-73.

14. Stingl JC, Kaumanns KL, Claus K, Lehmann ML, Kastenmuller $\mathrm{K}$, Bleckwenn $\mathrm{M}$, et al. Individualized versus standardized risk assessment in patients at high risk for adverse drug reactions 
(IDrug)—study protocol for a pragmatic randomized controlled trial. BMC Fam Pract. 2016;17:49.

15. Dechanont S, Maphanta S, Butthum B, Kongkaew C. Hospital admissions/visits associated with drug-drug interactions: a systematic review and meta-analysis. Pharmacoepidemiol Drug Saf. 2014;23(5):489-97.

16. Heringa M, Floor-Schreudering A, Tromp PC, de Smet PA, Bouvy ML. Nature and frequency of drug therapy alerts generated by clinical decision support in community pharmacy. Pharmacoepidemiol Drug Saf. 2016;25(1):82-9.

17. Cruciol-Souza JM, Thomson JC. Prevalence of potential drugdrug interactions and its associated factors in a Brazilian teaching hospital. J Pharm Pharm Sci. 2006;9(3):427-33.

18. Zwart-van Rijkom JE, Uijtendaal EV, ten Berg MJ, van Solinge WW, Egberts AC. Frequency and nature of drug-drug interactions in a Dutch university hospital. Br J Clin Pharmacol. 2009;68(2):187-93.

19. Astrand B, Astrand E, Antonov K, Petersson G. Detection of potential drug interactions-a model for a national pharmacy register. Eur J Clin Pharmacol. 2006;62(9):749-56.

20. Raschi E, Piccinni C, Signoretta V, Lionello L, Bonezzi S, Delfino $\mathrm{M}$, et al. Clinically important drug-drug interactions in polytreated elderly outpatients: a campaign to improve appropriateness in general practice. $\mathrm{Br} \mathrm{J}$ Clin Pharmacol. 2015;80(6):1411-20.

21. Bergk V, Gasse C, Rothenbacher D, Loew M, Brenner H, Haefeli WE. Drug interactions in primary care: impact of a new algorithm on risk determination. Clin Pharmacol Ther. 2004;76(1):85-96.

22. Egger SS, Drewe J, Schlienger RG. Potential drug-drug interactions in the medication of medical patients at hospital discharge. Eur J Clin Pharmacol. 2003;58(11):773-8.

23. Reimche L, Forster AJ, van Walraven C. Incidence and contributors to potential drug-drug interactions in hospitalized patients. J Clin Pharmacol. 2011;51(7):1043-50.

24. Nobili A, Pasina L, Tettamanti M, Lucca U, Riva E, Marzona I, et al. Potentially severe drug interactions in elderly outpatients: results of an observational study of an administrative prescription database. J Clin Pharm Ther. 2009;34(4):377-86.

25. Johnell K, Klarin I. The relationship between number of drugs and potential drug-drug interactions in the elderly: a study of over 600,000 elderly patients from the Swedish prescribed drug register. Drug Saf. 2007;30(10):911-8.

26. Secoli SR, Figueras A, Lebrao ML, de Lima FD, Santos JL. Risk of potential drug-drug interactions among Brazilian elderly: a population-based, cross-sectional study. Drugs Aging. 2010;27(9):759-70.
27. Blozik E, Signorell A, Reich O. How does hospitalization affect continuity of drug therapy: an exploratory study. Ther Clin Risk Manag. 2016;12:1277-83.

28. Mansur N, Weiss A, Hoffman A, Gruenewald T, Beloosesky Y. Continuity and adherence to long-term drug treatment by geriatric patients after hospital discharge: a prospective cohort study. Drugs Aging. 2008;25(10):861-70.

29. Martin P, Haefeli WE, Martin-Facklam M. A drug database model as a central element for computer-supported dose adjustment within a CPOE system. J Am Med Inform Assoc. 2004;11(5):427-32.

30. Hosia-Randell HM, Muurinen SM, Pitkala KH. Exposure to potentially inappropriate drugs and drug-drug interactions in elderly nursing home residents in Helsinki, Finland: a crosssectional study. Drugs Aging. 2008;25(8):683-92.

31. Ljung $\mathrm{R}, \mathrm{Lu} \mathrm{Y}$, Lagergren J. High concomitant use of interacting drugs and low use of gastroprotective drugs among NSAID users in an unselected elderly population: a nationwide register-based study. Drugs Aging. 2011;28(6):469-76.

32. Butkiewicz M, Restrepo NA, Haines JL, Crawford DC. Drugdrug interaction profiles of medication regimens extracted from a de-identified electronic medical records system. AMIA Jt Summits Transl Sci Proc. 2016;2016:33-40.

33. Roblek T, Vaupotic T, Mrhar A, Lainscak M. Drug-drug interaction software in clinical practice: a systematic review. Eur J Clin Pharmacol. 2015;71(2):131-42.

34. Schmiedl S, Rottenkolber M, Hasford J, Rottenkolber D, Farker $\mathrm{K}$, Drewelow B, et al. Self-medication with over-the-counter and prescribed drugs causing adverse-drug-reaction-related hospital admissions: results of a prospective, long-term multi-centre study. Drug Saf. 2014;37(4):225-35.

35. Ahn EK, Kam HJ, Park DK, Jung EY, Lee Y, Park RW. Differences among admitting departments in alerts and alert overrides for drug-drug interaction. Pharmacoepidemiol Drug Saf. 2014;23(4):390-7.

36. Bryant AD, Fletcher GS, Payne TH. Drug interaction alert override rates in the meaningful use era: no evidence of progress. Appl Clin Inform. 2014;5(3):802-13.

37. Slight SP, Seger DL, Nanji KC, Cho I, Maniam N, Dykes PC, et al. Are we heeding the warning signs? Examining providers' overrides of computerized drug-drug interaction alerts in primary care. PLoS One. 2013;8(12):e85071.

38. Kruse CS, Kristof C, Jones B, Mitchell E, Martinez A. Barriers to electronic health record adoption: a systematic literature review. J Med Syst. 2016;40(12):252. 